\title{
Use of the CRIB (clinical risk index for babies) score in prediction of neonatal mortality and morbidity
}

Richard H B de Courcy-Wheeler, Charles D A Wolfe, Anthony Fitzgerald, Maxine Spencer, Jonathan D S Goodman, Harold R Gamsu

\begin{abstract}
A prospective study of the outcome of care of a regional cohort of very low birthweight $(<1500 \mathrm{~g})$ and very preterm $(<32$ weeks) infants was carried out. Its aims were to assess the ability of the CRIB (clinical risk index for babies) score, rather than gestational age or birthweight, to predict mortality before hospital discharge, neurological morbidity, and length of stay, and to access CRIB score as an indicator of neonatal intensive care performance. 676 live births fulfilled the criteria and complete data were available for $643(95 \%)$. Compared with gestation and birthweight, CRIB was better for the prediction of mortality, was as good for the prediction of morbidity, and was not as good for the prediction of length of stay. CRIB adjusted mortality did not demonstrate better performance in units providing the highest level of care. Either the CRIB score was not sensitive to performance or the level 3 hospitals in this study were performing badly.

On the basis of this analysis purchasers and providers of neonatal intensive care cannot yet rely on the CRIB score as a performance indicator.
\end{abstract}

(Arch Dis Child 1995; 73: F32-36)

Keywords: CRIB score, very low birthweight infant, outcome.

Department of Public Health Medicine, United Medical and Dental Schools, Block 8 South Wing, St

Thomas's Hospital,

London SE1 7EH

R H B de CourcyWheeler

C D A Wolfe

M Spencer

A Fitzgerald

The Maidstone Hospital, Hermitage Lane, Maidstone J D S Goodman

Children Nationwide Neonatal Centre, King's College Hospital, London H R Gamsu

Correspondence to: Dr R de Courcy-Wheeler, Craigavon Area Hospital, 68 Lurgan Road Portadown, Craigavon BT 63 5QQ.

Accepted 7 April 1995
Health care professionals and purchasers of health care need to assess the requirements for neonatal intensive care, and to monitor the performance of units providing neonatal services. The only routinely available data in the United Kingdom are neonatal and birthweight specific mortality rates ${ }^{1}$ which take no account of case-mix and are not specific to neonatal care. Several scores have been published which use clinical details recorded at the time of admission to the neonatal unit and physiological variables recorded within the first 24 hours of life. ${ }^{2-5}$ The CRIB (clinical risk index for babies) score ${ }^{3}$ has been reported to be a better predictor of mortality than birthweight, and to correlate with morbidity at discharge from hospital, as measured by ultrasound evidence of major cerebral abnormality. The CRIB score has also been reported to take account of case-mix and to adjust crude mortality rates to allow comparison of the performance of neonatal intensive care units.
After such an adjustment, teaching hospitals performed better than non-teaching hospitals. ${ }^{3}$ The study was criticised for failing to define teaching hospitals ${ }^{6}$; doubts were expressed about the ability of CRIB to rank hospital performance ${ }^{67}$ and bias in case selection was suspected. ${ }^{8}$

This study examines the outcome of care of a regional cohort of very low birthweight $(<1500 \mathrm{~g})$ and very preterm $(<32$ weeks) infants. Its aims were to assess: (1) the ability of the CRIB score, compared with gestational age and birthweight, to predict mortality before hospital discharge, neonatal morbidity, and length of stay; and (2) the use of the CRIB score as an indicator of neonatal intensive care performance.

\section{Methods}

The South East Thames Low Birthweight Study collected data on all infants with a birthweight between 500 and $2499 \mathrm{~g}$ and born to mothers resident in the region between 1 September 1992 and 31 August 1993. Babies weighing less than $500 \mathrm{~g}$ were included if gestational age was 22 weeks or more. All data were collected prospectively from each of the hospitals serving regional residents by two researchers (R de C-W, MS). The total study population was 3456 infants, comprising $95 \%$ of births notified to the Regional Child Health Computer database. The present analysis was limited to liveborn very low birthweight $(<1500 \mathrm{~g})$ and very preterm ( $<32$ weeks) infants admitted to the special care baby unit (SCBU) and for whom the CRIB score would be relevant.

Six factors necessary for calculation of the CRIB score were collected - that is, birthweight, gestational age, the presence of congenital malformation(s) and maximum base excess, minimum and maximum appropriate inspired oxygen concentration in the first 12 hours. Mortality was defined as a death occurring before discharge from hospital. Neonatal neurological morbidity was defined as evidence of intraventricular haemorrhage (Papile grades 3 or 4) on cranial ultrasound scan. ${ }^{9}$ The CRIB score was divided into four subgroups: $0-5$, 6-10, 11-15 and more than 153. Gestation was rounded to 23 weeks or less, 32 weeks or more, and to whole weeks in between. Birthweight was subdivided into six groups: less than 500 g, 500-749, 750-999, $1000-1249,1250-1499$, and $1500+$. The relations of CRIB score, gestation, and 
Table 1 Hospital performance

\begin{tabular}{|c|c|c|c|c|c|c|}
\hline \multirow[b]{2}{*}{ Hospital } & \multicolumn{2}{|c|}{ Admissions to $S C B U^{\star}$} & \multicolumn{2}{|l|}{ Workload $^{\star}$} & \multirow{2}{*}{$\begin{array}{l}\text { Regionally } \\
\text { designated } \\
\text { NICU }\end{array}$} & \multirow{2}{*}{$\begin{array}{l}\text { Paneth } \\
\text { level } \\
\text { of } \\
\text { care }\end{array}$} \\
\hline & $\begin{array}{l}\text { Total } \\
n=\end{array}$ & $\begin{array}{l}<1500 \mathrm{~g} \\
(\%)\end{array}$ & $\begin{array}{l}\text { Category } 1 \\
\text { days/year }\end{array}$ & $\begin{array}{l}\text { Category } 2 \\
\text { days/year }\end{array}$ & & \\
\hline 1 & 246 & 27 & $799 \ddagger$ & 629 & Yes & 3 \\
\hline 2 & 414 & 25 & $1767 \ddagger$ & 1060 & Yes & 3 \\
\hline 3 & 600 & 12 & $816 \ddagger$ & 386 & & 2 \\
\hline $4 \dagger$ & & & $573 \ddagger$ & 287 & & 3 \\
\hline 5 & 446 & 10 & $314^{\circ}$ & 33 & & 2 \\
\hline 6 & 266 & 8 & 86 & 9 & & 1 \\
\hline 7 & 330 & 7 & 44 & 21 & & 2 \\
\hline 8 & 357 & 13 & 53 & 22 & & 1 \\
\hline 9 & 386 & 19 & $1485 \ddagger$ & 368 & Yes & 2 \\
\hline 10 & 181 & 12 & 80 & 79 & & 1 \\
\hline 11 & 209 & 15 & 287 & 98 & & 2 \\
\hline 12 & 463 & 12 & $677 \ddagger$ & 7 & Yes & 2 \\
\hline $13 t$ & & & 3 & 3 & & 1 \\
\hline 14 & 327 & 15 & 313 & 22 & & 2 \\
\hline $15 \dagger$ & & & 3 & 0 & & 1 \\
\hline $16^{\circ}$ & 174 & 11 & 66 & 2 & & 1 \\
\hline 17 & 210 & 7 & 7 & 1 & & 1 \\
\hline 18 & 406 & 21 & $1283 \ddagger$ & 540 & Yes & 3 \\
\hline
\end{tabular}

«Data for admissions and workload for the year 1990 taken from the annual report of the Regional Perinatal Monitoring Group. ${ }^{14}$

†Admission data for hospitals 3 and 4,12 and 13 , and 14 and 15 are combined. $¥$ High tAdmission data for hospitals 3 and 4,12 and 13 , and 14 and 15 are

birthweight to hospital mortality for all babies, and to morbidity for survivors were analysed using univariate analysis. Spearman's rank correlation coefficient was used to explore their association with length of stay.

Receiver operating characteristic (ROC) curves compared the performance of different tests, by plotting sensitivity or detection rate against 1-specificity (false positive rate). ${ }^{10}$ The best test is one which achieves the highest sensitivity for the lowest false positive rate. ROC curves were composed for CRIB score, birthweight, and gestation to assess the ability of each to predict hospital mortality and, among survivors, neurological morbidity.

Babies were allocated to the hospital which provided most of their care in the first 72 hours of life. ${ }^{3}$ Hospitals 1-18 were all within South East Thames region. Hospital number 19 comprised data from several hospitals out of the region in which babies of resident mothers were delivered or to which they were transferred. In the analysis of their performance, hospitals 1-18 were categorised in three ways (table 1): level of care; workload; and designation.

Paneth et al described three levels of neonatal intensive care with level 1 being the highest level of care. ${ }^{11}$ Field et $a l^{12}$ related workload to the number of hours of ventilation per year, which is equivalent to category 1 maximal intensive care, ${ }^{13}$ in addition to specialist neonatal consultant input and 24 hour middle grade medical cover. A high workload was defined as more than 500 days of category 1 care per year. South East Thames Regional Health Authority has designated five neonatal units to be tertiary referral neonatal centres. ${ }^{14}$

Crude hospital mortality rates were adjusted for CRIB using multiple logistic regression analysis to compare the performance of individual neonatal units, as described by the International Neonatal Network, ${ }^{3}$ and between the three different categories of units. The rankings of the individual units were compared with indirect standardised mortality ratios. The standardised morality ratio (SMR) is described by the equation:

$$
\mathrm{SMR}=\frac{0_{1}+0_{2}+0_{3}+0_{4}}{(\mathrm{n} 1 \times \mathrm{E} 1)+(\mathrm{n} 2 \times \mathrm{E} 2)+(\mathrm{n} 3 \times \mathrm{E} 3)+(\mathrm{n} 4 \times \mathrm{E} 4)} \times 100
$$

where $\mathrm{n}$ is the number of babies, $\mathrm{E}$ is the expected mortality rate, and 0 is the observed number of deaths among all regional births in each of the four subgroups $(0-5,6-10,11-15$, 16+) of the CRIB score.

The data from this study were used to recreate the CRIB score by repeating the original methodology. This provided new values for the components of the six factors in the score and improvements to the score were then tested.

\section{Results}

There were 676 babies admitted, of less than 32 weeks of gestation or weighing less than $1500 \mathrm{~g}$. Analysis was restricted to the 643 with complete CRIB data. Table 2 shows the numbers of babies treated, numbers of deaths, and mean CRIB scores in each hospital. There were significantly more deaths among the cases with an incomplete CRIB score $\left(13 / 33=39 \cdot 4 \%\right.$ v $101 / 643=15 \cdot 7 \% ; \chi^{2}=12 \cdot 56$; $\mathbf{P}=0.0001$ ). However, six of the deaths were in babies admitted for terminal care. The other seven lived for 12 hours or more, had respiratory support, and would have been expected to have had a blood gas analysis performed, but some data were missing. After excluding the six babies admitted for terminal care there was no longer a significant difference in mortality $\left(7 / 27=25 \cdot 9 \%\right.$ v $101 / 643=15 \cdot 7 \% ; \chi^{2}=1 \cdot 338$; $\mathrm{P}=0.09$ ).

CRIB score, gestation, and birthweight were all significant univariate predictors of hospital mortality $(P<0.0001)$. For example, mortality in hospital rose from 3\% (14/464) with a CRIB score of $0-5$ to $94 \%(15 / 16)$ with a score $>15$. Mortality in hospital rose from 7\% (9/129) in babies born at 31 weeks' gestation to $61 \%$ (11/18) at 24 weeks. Mortality in hospital rose from $6 \%(9 / 152)$ in those whose birthweight was $>1249 \mathrm{~g}$ to $73 \%(70 / 96)$ in those weighing $<750$ g. The ROC curve showed that CRIB score predicted mortality with greater sensitivity, at all levels of specificity, than did gestation or birthweight (fig 1).

Table 2 Numbers treated, number of deaths and mean CRIB score by hospital

\begin{tabular}{lrrl}
\hline Hospital & Total & Deaths & Mean CRIB score \\
\hline 1 & 74 & 13 & $3 \cdot 5$ \\
2 & 103 & 21 & $4 \cdot 4$ \\
3 & 36 & 8 & $4 \cdot 1$ \\
4 & 45 & 6 & $3 \cdot 5$ \\
5 & 21 & 1 & $1 \cdot 6$ \\
6 & 13 & 0 & $2 \cdot 0$ \\
7 & 22 & 1 & $2 \cdot 1$ \\
8 & 10 & 0 & $2 \cdot 2$ \\
9 & 95 & 18 & $4 \cdot 9$ \\
10 & 5 & 0 & $2 \cdot 0$ \\
11 & 33 & 11 & $5 \cdot 6$ \\
12 & 39 & 7 & $4 \cdot 6$ \\
13 & 1 & 0 & 0 \\
14 & 22 & 2 & $2 \cdot 9$ \\
15 & 0 & 0 & - \\
16 & 5 & 0 & $3 \cdot 8$ \\
17 & 2 & 0 & $1 \cdot 0$ \\
18 & 54 & 4 & $2 \cdot 9$ \\
19 & 63 & 9 & $5 \cdot 6$ \\
Total & 643 & $101(16 \%)$ & $4 \cdot 0$ \\
\hline
\end{tabular}




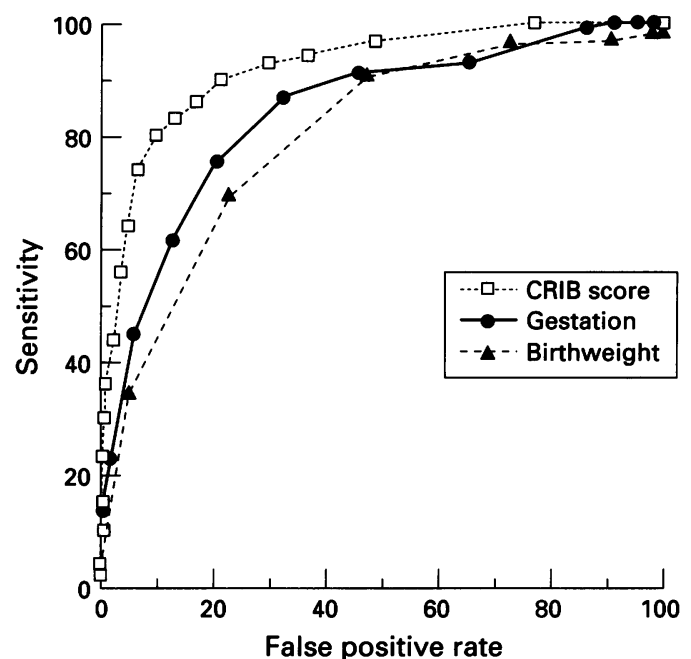

Figure 1 ROC curves for prediction of mortality in hospital by CRIB score, gestation, and birthweight $(n=643)$.

Similarly, CRIB score, gestation, and birthweight were all significant univariate predictors of neurological morbidity ( $P<0 \cdot 0001)$. Neurological problems increased from 5\%(22/450) with a CRIB score of $0-5$ to $28 \%(5 / 18)$ with a score of $>11$. These problems increased from $2.7 \%(5 / 183)$ in those born at 31 weeks' gestation or more to $25 \%(2 / 8)$ in those born at less than 25 weeks' gestation, and increased from $3.5 \%(10 / 287)$ in those whose birthweight was $>1249 \mathrm{~g}$ to $23 \%(6 / 26)$ in those weighing $<750 \mathrm{~g}$. However, for the prediction of morbidity, the ROC curve showed no difference between CRIB score, gestation, or birthweight (fig 2).

CRIB score, gestation at birth, and birthweight were correlated strongly with length of stay, the Spearman rank correlations being $0.612,-0.75$, and -0.766 , respectively.

The crude odds of death, the odds of death adjusted for CRIB score, and standardised mortality ratios are shown in table 3. After allowing for ex utero transfers, seven level 1 hospitals had zero mortality and were omitted from the table. There was no significant difference in mortality or adjusted mortality

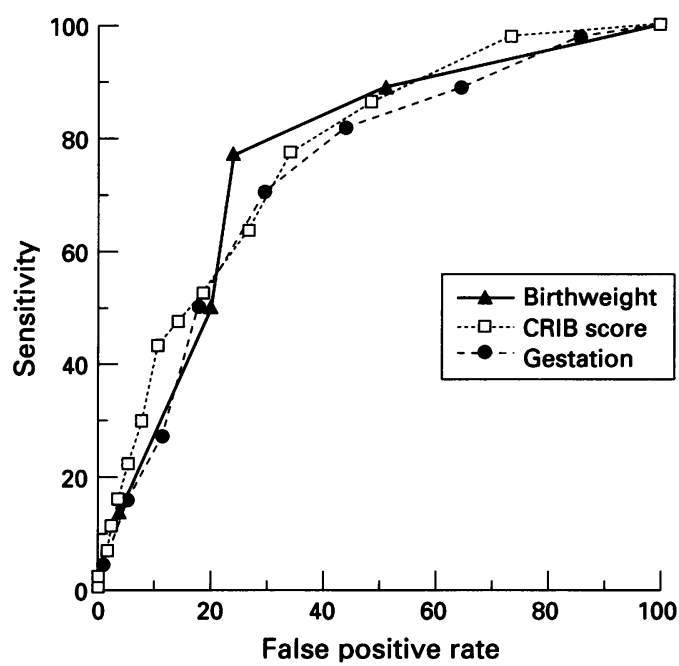

Figure 2 ROC curves for prediction of intracerebral morbidity (IVH Papile grade III or IV) in survivors $(n=542)$ by CRIB score, gestation, and birthweight.
Table 3 Comparison of hospital mortality rates and ranks

\begin{tabular}{|c|c|c|c|c|c|c|}
\hline \multirow[b]{2}{*}{ Hospital ${ }^{\star}$} & \multicolumn{2}{|c|}{$\begin{array}{l}\text { Crude odds } \\
\text { (No of deaths) }\end{array}$} & \multicolumn{2}{|c|}{$\begin{array}{l}\text { Adjusted odds } \\
\text { by CRIB }\end{array}$} & \multicolumn{2}{|c|}{$\begin{array}{l}S M R \\
\text { by } C R I B\end{array}$} \\
\hline & Odds & Rank & Odds & Rank & $S M R$ & Rank \\
\hline $\begin{array}{c}7 \\
18 \dagger \\
14 \\
12 \dagger \\
5 \\
9 \dagger \\
4 \\
2 \dagger \\
1^{\star} \\
3 \\
11\end{array}$ & $\begin{array}{l}0.22(1) \\
0.38(4) \\
0.47(2) \\
1.03(7) \\
0.24(1) \\
1 \cdot 10(18) \\
0.70(6) \\
1.22(21) \\
1.00(13) \\
1.34(8) \\
2.35(11)\end{array}$ & $\begin{array}{r}1 \\
3 \\
4 \\
7 \\
2 \\
8 \\
5 \\
9 \\
6 \\
10 \\
11\end{array}$ & $\begin{array}{l}0.27 \\
0 \cdot 30 \\
0 \cdot 33 \\
0.52 \\
0.52 \\
0.55 \\
0 \cdot 80 \\
0 \cdot 84 \\
1 \cdot 00 \\
1 \cdot 20 \\
1 \cdot 48\end{array}$ & $\begin{array}{r}1 \\
2 \\
3 \\
4 \\
5 \\
6 \\
7 \\
8 \\
9 \\
10 \\
11\end{array}$ & $\begin{array}{r}57 \\
66 \\
75 \\
90 \\
80 \\
91 \\
109 \\
109 \\
121 \\
128 \\
130\end{array}$ & $\begin{array}{r}1 \\
2 \\
3 \\
5 \\
4 \\
6 \\
7 \\
8 \\
9 \\
10 \\
11\end{array}$ \\
\hline
\end{tabular}

^Seven hospitals had zero mortality. Although not excluded from the analysis, they are excluded from the table.

tDesignated regional neonatal intensive care unit.

between the remaining 11 hospitals $(P>0 \cdot 5)$. The odds of death were higher, both before and after adjustment for case-mix in level 3, for high workload and designated neonatal units compared with the rest, but the differences were not significant (table 4).

New values for the separate components of CRIB, derived from the data in this study, gave increased weight to low gestation ( $\leqslant 24$ weeks). Low gestation scored $1 / 23$ in the original CRIB and $6 / 32$ in the new derivation. There was a small, significant improvement in fit when the score was based on four instead of two gestational age categories, but the change in the ROC curve of mortality in hospital was minimal.

\section{Discussion}

As far as we know, this is the first study to evaluate CRIB in a geographical cohort of infants. Data for the score were easy to collect and could readily be incorporated into any register of very low birthweight infants. To interpret the score, data from each centre need to be pooled, which means that individual hospitals lose sight of their own data and this reduces the impetus to collect it. The SMR method, which computes adjusted risk, can be calculated locally once expected mortality rates for each subgroup of the CRIB score are known. In this study the standard population, from which the expected mortality rates were derived, was the regional cohort. This is not necessarily the ideal standard and there is therefore a danger that hospitals will interpret a low SMR as a very good result when it may only be relatively good. Notwithstanding, table 3 shows that hospital ranking by SMR is almost identical with that using CRIB, the difference being due to small numbers and wide confidence intervals. Central collation of CRIB data could be justified by encouraging hospitals to use CRIB when calculating SMRs.

Table 4 Comparison of crude and CRIB adjusted odds of death between Paneth level 3 hospitals, designated NICUs, high workload hospitals, and remainder

\begin{tabular}{lll}
\hline & $\begin{array}{l}\text { Crude mortality } \\
\text { odds ratio }(95 \% \text { CI) }\end{array}$ & $\begin{array}{l}\text { CRIB adjusted } \\
\text { odds ratio }(95 \% \text { CI })\end{array}$ \\
\hline Paneth level 3 & $1.01(0.65,1.58)$ & $1.28(0.68,2.41)$ \\
Designated NICU & $1.35(0.84,2.17)$ & $1.07(0.54,2.11)$ \\
High workload & $1.66(0.92,2.99)$ & $1.43(0.60,3.42)$ \\
\hline
\end{tabular}




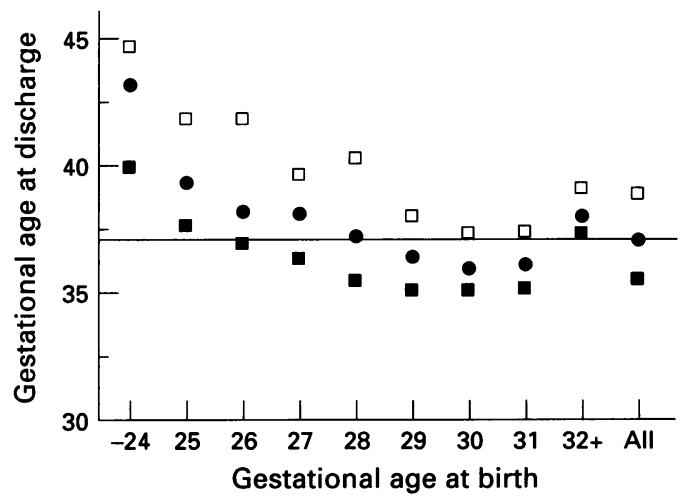

Figure 3 Median gestational age at discharge from hospital (interquartile range) in survivors $(n=542)$.

Compared with gestation and birthweight CRIB was better at predicting mortality, was as good at predicting morbidity, but was less good at predicting length of stay. Date of discharge from hospital is an arbitrary endpoint, influenced by differing policies of care rather than quality of care or illness severity. However, it corresponds well to post-conceptional age ${ }^{15}$ and was remarkably constant for babies of all gestational ages in this study (fig 3). Thus it seems reasonable to use mortality in hospital as an outcome measure. CRIB was then the best predictor of mortality in hospital. At a false positive rate of $5 \%$, CRIB had a sensitivity of $67 \%$ compared with a sensitivity of $41 \%$ for gestation and for birthweight.

A score which can accurately predict mortality could be used by purchasers of health care to refuse to provide expensive care for babies with a high score. This would be an abuse of an epidemiological tool in individual cases. There were 16 babies with a CRIB score of 16 or more who performed their own triage. Fifteen died after using less than a total of 25 days of intensive care, a fraction of the per cent of days spent in category 1 intensive care each year. Though the decision to treat very small babies poses many ethical problems, ${ }^{16}$ the CRIB score demonstrates that cost is a minor factor.

Cranial ultrasound findings in the very low birthweight baby have been shown to correlate strongly with their neurodevelopmental outcome at 4 years of age ${ }^{17}$ and CRIB has been shown to be highly correlated with brain ultrasound findings. ${ }^{3}$ It does not necessarily follow that CRIB can predict neurodevelopmental outcome. In the current study, although CRIB, gestation at birth, and birthweight were all significantly associated with cranial ultrasound findings, they all had low sensitivity of about $20 \%$ at a $5 \%$ false positive rate. Thus the CRIB score as currently calculated does not improve on existing data (such as birthweight and gestational age) for the prediction of brain ultrasound abnormalities and, unlike gestation at birth and birthweight, ${ }^{18}$ babies have not yet been followed up for long enough to demonstrate an association with neurodevelopmental outcome.

Traditionally, birthweight specific mortality rates have been used to assess the outcome of neonatal and obstetric care ${ }^{1}$ despite evidence that gestation at birth is a superior measure. ${ }^{19}$
The ROC curve of mortality in hospital also shows that gestation at birth is better than birthweight. It is surprising, therefore, that gestation at birth made such a small contribution to the overall CRIB score, and it has been excluded in other similar scores. ${ }^{45}$ Yet, more emphasis on gestation in the CRIB score failed to improve its application in practice.

Hospitals were defined as teaching or nonteaching in the original paper on $\mathrm{CRIB}^{3}$ depending on where medical students received most of their clinical training. ${ }^{20}$ This definition gave no clear idea as to the real differences among hospitals with regard to neonatal care service provision. Classifications by workload ${ }^{12}$ or level of care ${ }^{11}$ are reproducible and comparable, and future studies on hospital performance should use similar standardised criteria. The interpretation of CRIB when used to measure hospital performance was difficult. Even over a one year period seven hospitals had too few cases to create a meaningful score and, due to implementation of a policy of in utero and ex utero transfer of high risk fetuses and neonates, they had mortality rates of zero. If CRIB was functioning as a measure of performance the 'best' hospitals (level 3, high workload, designated NICU) would be expected to have a higher rank. This did not occur either because the level 3 hospitals in South East Thames were performing badly or because CRIB was not sensitive to the performance it purported to measure. The excess mortality may equate with unmeasured risk rather than ineffective care. ${ }^{17}$ Furthermore, mortality may not be the best measure of quality of care as hospitals with low mortality may discharge babies with higher levels of morbidity. Until CRIB is evaluated further it cannot yet be used by purchasers or providers of neonatal intensive care as a sensitive indicator of hospital performance.

Thanks are due to South East Thames Regional Health Authority for funding ( $R$ de $C-W, M S$ ) and to the health care Authority for funding (R de $\mathrm{C}-\mathrm{W}, \mathrm{MS}$ ) and to the health care
professionals in all the units for permitting us access to their professid

1 Office of Population Censuses and Surveys. Birthweight Statistics Series DH3. London: HMSO, 1993.

2 Horbar J, Onstad L, Wright E. Predicting mortality risk for infants weighing $510-1500 \mathrm{~g}$ at birth: a National Institutes of Health Neonatal Research Network report. Crit Care Med 1993; 21: 12-8.

3 International Neonatal Network. The CRIB (clinical risk index for babies) score: a tool for assessing initial neonatal risk and comparing the performance of neonatal intensive care units. Lancet 1993; 342: 193-8.

4 Richardson D, Phibbs C, Gray J. Birthweight and illness severity: independent indicators of disease severity. severity: independent indicat

5 Richardson D, Gray J, McCormick M, Goldman D. Score for neonatal acute physiology: a physiology severity index for neonatal acute physiology: a physiology severity index
for neonatal intensive care. Pediatrics 1993; 91: 617-23. for neonatal intensive care. Pediatrics 1993; 91
Grant J. The CRIB score. Lancet 1993; 342: 612 .

6 Grant J. The CRIB score. Lancet 1993; 342: 612. score. Lancet 1993; 342: 612-3.

8 Sepkowitz S. The CRIB score. Lancet 1993; 342: 938.

9 Papile L-A, Burstein J, Burstein R, Koffler H. Incidence and evolution of subependymal and intraventricular haemorrhage: a study of infants with birthweights less than 1500 g. F Pediatr 1978; 92: 529-34

10 Altman D, Bland J. Diagnostic tests 3: receiver operating characteristic plots. BMF 1994; 309: 188

11 Paneth N, Kiely JL, Wallenstein S, Marcus M, Pakter J, Susser $\mathbf{M}$. Newborn intensive care and neonatal mortality in low birthweight infants. $N$ Engl $\mathcal{f}$ Med 1982; 307: in low birt

12 Field D, Hodges S, Mason E, Burton P. Survival and place of treatment after premature delivery. Arch Dis Child 1991; 66: 408-11.

13 Cooke R. Report of a working group of the British Association of Perinatal Medicine and Neonatal Nurses 
Association on categories of babies requiring neonatal care. Arch Dis Child 1992; 67: 868-9.

14 Regional Perinatal Monitoring Group (RPMG). Perinatal Profile 1990. London: South East Thames Regional Health Authority, 1992.

15 Powell P, Powell C, Hollis S, Robinson M. When will my baby go home? Arch Dis Child 1992; 67: 1214-6.

16 Roberton N. Should we look after babies less than $800 \mathrm{~g}$ ? Arch Dis Child 1993; 68: 326-9.

17 Costello A, Hamilton P, Baudin J. Prediction of neurodevelopmental impairment at four years from brain ultrasound appearance of very preterm infants. Dev Med Child Neurol 1988; 30: 711-22.

18 Johnson A, Townshend P, Yudkin P, Bull D, Wilkinsom A Functional abilities at age 4 years of children born before 29 weeks of gestation. BMF 1993; 306: 1715-8.

19 Verloove-Vanhorick SP, Verwey RA, Brand R, Bennebroek Gravenhorst J, Keirse MJNC, Ruys JH. Neonatal mortality risk in relation to gestational age and birthweight. Lancet 1986; i: 55-7.

20 Tarnow-Mordi W, Cooke R, Parry G, Ogston S. The CRIB score. Lancet 1993; 342: 613. 